\title{
Complications of Anterior Chamber Lens Implants and Their Effects on the Endothelium
}

\author{
R. F. WALTERS $\dagger$, J. I. McGILL $\dagger$, M. BATTERBURY $\dagger$, J. D. WILLIAMS* \\ Southampton
}

\begin{abstract}
Summary
A five-year follow-up study of 186 eyes which were subject to intracapsular cataract extraction and rigid anterior chamber lens implantation is reported. Ninety-two per cent of cases achieved a visual acuity of $6 / 12$ or better. Serial corneal endothelial cell counts were performed. In 37 pairs of eyes the median difference in operative endothelial cell loss between the operated and un-operated eyes was $-7.3 \%(95 \%$ Confidence Interval from -8.7 to $-6.1 \%$ ). Iris tuck occurred in $22.0 \%$ and late 'iris ovalling' developed in a further $15.6 \%$ of eyes. The median operative endothelial cell loss for those eyes with iris tuck was $\mathbf{- 9 . 7 \%}$ and this was significantly higher than that of eyes with no long-term complications (median loss $=-7.3 \%$ ). The median operative endothelial cell loss for those eyes which developed late ovalling was $\mathbf{- 8 . 0 \%}$ and this was not significantly greater than that of the eyes with no long-term complications $(p=0.745)$. There was a progressive median endothelial cell loss for all operated eyes and this progressive cell loss was significantly greater for those eyes with iris tuck when compared with those with no complications $(p=0.045)$.
\end{abstract}

Over recent years intraocular lens implantation following cataract extraction has become generally accepted. Until a few years ago most implants were either of the 'anterior chamber' or 'iris-supported' varieties used in combination with the intracapsular technique of cataract extraction. More recently extracapsular cataract extraction and posterior chamber lens implantation has gained favour. In the early days endothelial decompensation was a major complication of lens implantation but since the introduction of the operating microscope, new lens designs and visco-elastic substances, this has become less of a potential hazard. The advent of specular endothelial cell photo-microscopy has provided one method of assessing the effects of lens implantation on the endothelium. Complications have been reported for both anterior and posterior chamber implants but the long-term effects on the eye of modern implants have yet to be evaluated.

This paper describes the result of a prospective study assessing the effects on the endothelium of intracapsular cataract extraction with rigid anterior lens implantation and the associated complications. The early results of this study were reported by McGill and Liakos in $1985 .{ }^{1}$ Longer term follow-up results are now available.

\section{Method}

This study is based on 186 eyes (from 169 patients) which underwent intracapsular cataract extraction and intraocular lens implantation. These were studied on a prospective 
basis over a median period of 24 months, from the time of surgery. The range of follow up was from 4 to 68 months. A Choyce Mark IX rigid anterior chamber lens was implanted in all cases. All the patients were under the care of one Consultant (J. I. M.) and all the operations were performed by him.

Each patient had bilateral central corneal endothelial cell specular photomicrographs performed pre-operatively and at regular intervals post-operatively (six weeks, three months, six months, one year and thereafter annually). It was not possible to achieve, with accuracy, the desired timings in all cases. The endothelial photo-micrographs were taken using a Pocklington wide field contact specular microscope. The photographs were enlarged to $150 \mathrm{~mm}$ by $100 \mathrm{~mm}$ and an estimate of the cell density made by counting with the aid of a Keeler standard grid. The cells within the grid and those cells touching two consecutive borders were counted. Those cells touching the other two borders were not counted. Each photograph was counted three times and the average cell count recorded. The first post-operative cell count was usually taken at six weeks after surgery but was accepted as a first post-operative count up to six months post-operatively. The operative cell loss for each eye was taken as the difference between the first pre-operative count and the post-operative count. Thereafter con-

Table I Median Operative Cell Loss (all eyes) versus Controls

\begin{tabular}{|c|c|}
\hline \multicolumn{2}{|l|}{ All operated eyes. } \\
\hline Median \% cell loss & $-8.0 \%$ \\
\hline Range & $-24.5 \%$ to $+7.1 \% *$ \\
\hline Number of eyes & 85 \\
\hline \multicolumn{2}{|l|}{ Control eyes (unoperated). } \\
\hline Median \% cell loss & $-0.7 \%$ \\
\hline Range & $-12.0 \%$ to $+1.7 \%$ \\
\hline Number of eyes & 48 \\
\hline \multicolumn{2}{|c|}{$\begin{array}{l}\text { Paired comparison of operated eyes with fellow } \\
\text { unoperated eyes. }\end{array}$} \\
\hline Number of pairs of eyes & 37 \\
\hline $\begin{array}{l}\text { Median difference } \\
\quad \text { (operated-unoperated) }\end{array}$ & $-7.3 \%$ \\
\hline Wilcoxon paired rank sum test & $\mathrm{p}<0.001$ \\
\hline $\begin{array}{l}95 \% \text { Confidence Interval for } \\
\text { median difference }\end{array}$ & $-8.7 \%$ to $+6.1 \%$ \\
\hline
\end{tabular}

${ }^{*}$ A positive figure indicates a cell gain, a negative figure indicates a cell loss. tinued cell loss was taken as the difference between the first post-operative count and subsequent counts. In 37 cases the fellow eye (which had not been operated upon) was taken as the normal and estimates of normal cell loss per year calculated. This normal cell loss was then subtracted from the cell losses of the operated eyes to give the net cell loss in these eyes. Those eyes which were subject to operative or post-operative complications were analysed as separate subsets. The main complications studied were pupil peak due to lens implant tuck, late development of an oval pupil (which was not due to implant tuck), lens wobble/instability (e.g. rotation), macular oedema and persistent uveitis.

In this series every effort has been made to produce accurate endothelial cell counts. Twenty per cent of the original cell counts in the first series were checked on a blind basis and were found to agree to within $1 \%$ of the original count. However, in the follow up study five observers have been used and this will clearly have introduced a source of 'between-observer' variability. Specular endothelial photo-micrographs were taken of the central area of the cornea in each case but no attempt was made to locate the same area for cell counting by using posterior corneal rings. In addition, no account has been taken of cell morphology.

The rate of continued cell loss was estimated for each eye using a linear regression of cell loss on time. The yearly rate of cell loss was then compared between different subgroups of eyes using the Mann-Whitney $U$ Test (to allow for certain outlying values). All statistical procedures were performed using the statistical computer package MINITAB ${ }^{2}$

\section{Findings}

The average age of the patients at the time of operation was 74 years (range 48 to 91 years). The average pre-operative endothelial cell count was 2463 cells $/ \mathrm{mm}^{2}$ (range 1480 to 3260 cells $/ \mathrm{mm}^{2}$ ). In all operated eyes with available data $(\mathrm{n}=85)$ the median operative cell loss was $-8.0 \%$ (range $-24.5 \%$ to $+7.1 \%$ ) whereas in all unoperated eyes $(n=48)$ the median loss was $-0.7 \%$ (range $-12.0 \%$ to $+1.7 \%$ ) (Table I). In 37 cases we were able to compare cell loss in matched pairs of eyes 
Table II Incidence of long term post-operative complications

\begin{tabular}{lcc}
\hline & Number & \% of total \\
\hline No complications & 95 & 51.1 \\
Iris Tuck & 41 & 22.0 \\
Late Ovalling & 29 & 15.6 \\
Macular oedema & 8 & 4.3 \\
Lens migration & 13 & 5.9 \\
Lens wobble & 13 & 5.9 \\
Topical steroids & & \\
for one year or more & 15 & 8.1 \\
Total Eyes Studied & $186^{*}$ & 100.0 \\
\hline
\end{tabular}

* A number of eyes had more than one long term complication (see text).

where one eye had been operated upon and the other not. In these cases the median difference in cell loss between operated and unoperated eyes was $-7.3 \%$ (Wilcoxon paired rank sum test, $\mathrm{n}=37, \mathrm{p}<0.001)$. This comparison was not possible for all the cases as some patients had had previous cataract surgery to the other eye or the endothelial cell photographs were not available or unreadable. $92.3 \%$ of the eyes operated upon achieved a vision of $6 / 12$ or better.

$51.1 \%$ (95) of the operated eyes had no long-term ocular complications, (Table II). Our interest, however, centered on those eyes which were noted to have one of two complications. The first complication was that of 'iris tuck'. In these eyes the feet of the intraocular lens implant lens were tucked into the iris at operation, rather than being placed in the iridocorneal angle (Fig. 1). This group comprised $41(22 \%)$ of the total (Table II). The second complication was 'late iris ovalling', in which there was no evident iris tuck by the lens implant but in which the pupil later became oval (Fig. 2). This occurred in 29 $(15.6 \%)$ of the operated eyes studied (Table II).

In those eyes with no long-term post-operative complications ('normals') the median operative endothelial cell loss was found to be $-7.3 \%$ (Table III). Thereafter, the median rate of continued endothelial cell loss was estimated to be $-0.8 \%$ per year (see Table IV). However, this was not found to be statistically significant when compared with no change (Wilcoxon rank sum test, $\mathrm{n}=35, \mathrm{p}=0.473$, $95 \% \mathrm{CI}-1.28$ to $+0.93 \%$ per year $)$.
The median operative endothelial cell loss in the iris tuck group was $-9.7 \%$ (Table III) which was significantly greater $(p=0.037)$ than that in those eyes with no complications. In addition the endothelial cell loss continued progressively at a median rate of $-2.2 \%$ per year (Table IV). This rate of endothelial cell loss was significantly greater than that for the uncomplicated eyes $(\mathrm{p}=0.045$, Table IV). Of the 41 eyes with iris tuck, four required steroids for a year or more because of persistent anterior uveitis. Three others had persistent keratic precipitates (KP) on the implant. Thus seven $(17.1 \%)$ of the 41 eyes with iris tuck showed evidence of a continuing uveitis. Ectropion uveae developed in six $(14.6 \%)$ of these 41 patients (Fig. 3).

In the group of 29 eyes with late iris ovalling the median operative cell loss $(-8.0 \%)$ was comparable with that of the uncomplicated eyes $(p=0.745)$ and less (but not significantly so, $p=0.110)$ than that of the eyes with iris tuck $(-9.7 \%)$. But, there again appeared to be a progressive loss of endothelial cells for this group over the study period at a median rate of $-1.4 \%$ per year (Table IV). When compared with the rate of the uncomplicated eyes this did not quite assume statistical significance $(p=0.063$, Table IV). Six $(20.7 \%)$ of these 29 eyes required topical steroid treatment for a year or more. A further six (20.7\%) had persistent KP on the lens. Thus 12 $(41.4 \%)$ of the 29 with late iris ovalling had evidence of long-term uveitis.

In thirteen eyes $(7.0 \%)$ the lens implant was believed to have moved post-operatively

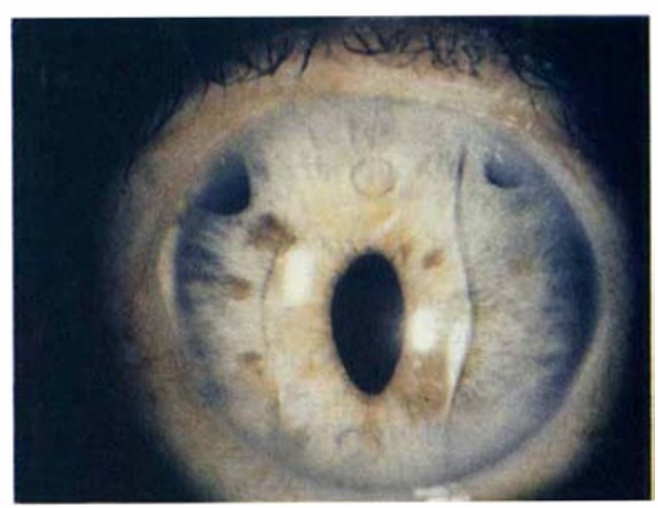

Fig. 1 'Iris Tuck'. 


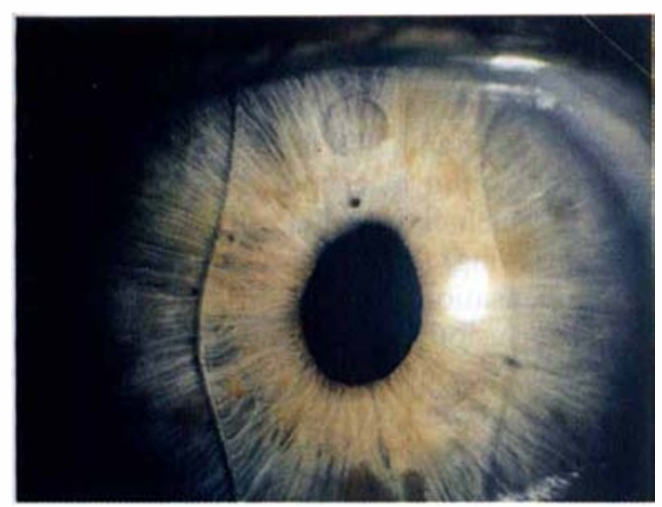

Fig. 2 'Late Iris Ovalling'.

(Table II). One of these had iris tuck and one had late iris ovalling. None had overt clinical signs of a prolonged uveitis. Lens implants in a further 13 eyes $(7.0 \%)$ were reported as showing wobble, though usually only slight.

Fifteen eyes $(8.1 \%)$ required topical steroids (for anterior uveitis) for a period of 12 months or longer (range 12-58 months, average 19.1 months). As mentioned above, four of these had iris tuck and a further six developed late iris ovalling (Table II). Eight eyes $(4.3 \%)$ developed clinical macular oedema (Table II). One of these had iris tuck and two others developed an oval pupil during follow up. In each of these last four groups (those with macular oedema, lens migration, lens wobble, and those on long-term steroids) there were insufficient data on endothelial cell loss to recognise patterns of cell loss or to enable a statistical comparison with other groups.

None of the eyes studied developed endothelial decompensation with resultant corneal oedema.

\section{Discussion}

In this study the findings which have most aroused our interest are the operative endothelial cell losses and the apparent progressive cell loss in those eyes with iris tuck and late iris ovalling. Those eyes in which iris tuck occurred had a significantly increased operative endothelial cell loss when compared with the uncomplicated group. Those eyes which developed "late ovalling" of the iris did not have an operative cell loss much different to that of the uncomplicated eyes. This implies that the surgery in the 'late ovalling' group was as straightforward as the uncomplicated eyes and that any cell loss thereafter was due to causes other than the surgery.

The uncomplicated eyes, 'iris tuck' and 'late ovalling' groups would all appear to show a trend of progressive endothelial cell loss. This

Table III Operative endothelial cell loss

\begin{tabular}{llcccc}
\hline Major complication & $n$ & median* & range & $p$-value & $95 \%$ CI \\
\hline Uncomplicated & 40 & -7.3 & -18.3 to +7.1 & - & - \\
Iris Tuck & 20 & -9.7 & -24.5 to -1.0 & 0.036 & $(-5.1,+0.1)$ \\
Late Ovalling & 14 & -8.0 & -14.7 to -0.8 & 0.745 & $(-2.7,+2.0)$ \\
\hline
\end{tabular}

$n=$ number of eyes with operative cell loss data available.

$p$-value $=p$-value from Mann-Whitney $U$ Test comparing each group with the uncomplicated eyes.

$95 \% C I=95 \%$ confidence interval for difference in medians compared to the uncomplicated eyes.

* Note: negative values indicate a \% cell loss.

Table IV Estimated annual continued \% cell loss

\begin{tabular}{lcccc}
\hline Major complication & $n$ & $\begin{array}{c}\text { Median \% cell } \\
\text { loss per year* }\end{array}$ & p-value & $95 \%$ CI \\
\hline Uncomplicated & 35 & -0.8 & $-\overline{045}$ & $(-4.0,0.0)$ \\
Iris tuck & 28 & -2.2 & 0.063 & $(-3.5,+0.1)$ \\
Late ovalling & 28 & -1.4 & 0.063 \\
\hline
\end{tabular}

$n=$ number of eyes with continued cell loss data available.

p-value = p-value from Mann-Whitney $U$ Test comparing each group with the uncomplicated eyes.

$95 \% C I=95 \%$ confidence interval for difference in medians compared to the uncomplicated eyes.

* Note: negative values indicate a \% cell loss. 


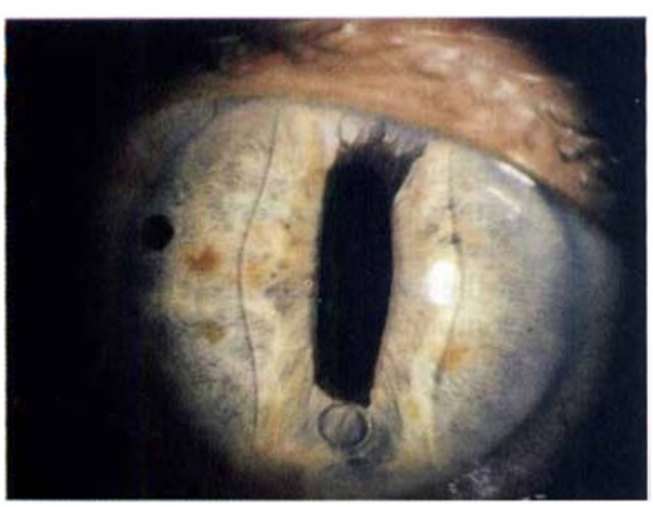

Fig. 3 Ectropion Uveae and Iris Tuck.

progressive cell loss is statistically significant for the 'late ovalling' group, almost significant for the 'iris tuck' group but not significant for the uncomplicated eyes. It is therefore possible to surmise that complications tend to produce a continuing cell loss. We feel that these trends merit serious consideration and follow up.

Late ovalling of the pupil with rigid anterior chamber lenses has been recognised previously $^{3,4}$ and there is evidence ${ }^{4,5,6,7,8}$ that a chronic low grade uveitis (often clinically undetectable) is associated both with late iris ovalling and iris tuck. This inflammation may be the underlying cause of a persistent endothelial cell loss. ${ }^{4,8,9}$ The uveitis could be due to irritation of the iris by the feet of the lens. It is suggested in the cases of late ovalling, although there is no overt tuck, that the feet are, or become, malpositioned in the iridocorneal angle and either rub against the root of the iris or slip into the peripheral iris tissue producing iris fibrosis or ischaemic atrophy.

The proportion of those eyes with iris tuck or late ovalling found in this study is similar to that reported elsewhere,,$^{3,4,7}$ Ectopian uveae has also been reported by others, ${ }^{10,11}$ in association with rigid anterior chamber lens implants and it has been suggested ${ }^{10}$ that this is caused by ischaemic atrophy of the iris stroma in association with iris tuck by the lens. It is interesting to note that post mortem studies ${ }^{7}$ have shown areas of focal obliteration of the arterial circle of the iris with anterior chamber lenses.

The figures for post operative visual acuity achieved in this study are broadly similar to those reported in other studies of cataract extraction and lens implantation..$^{4,7,8,12,13}$ The absence of endothelial decompensation in all eyes in this study is encouraging, but in those eyes in which endothelial cell loss appears to be continuing, the question arises of corneal decompensation in the future.

In conclusion, further long-term studies are required to monitor the effects of intraocular lens implants and their complications, especially if we are to feel confident about inserting lens implants into age groups other than the elderly.

\section{References}

${ }^{1}$ McGill K and Liakos G: Complications of Anterior Chamber Intraocular Lenses and Their Effect on the Endothelium. Trans Ophthalmol. Soc. U.K. 1985, 104: 273-7.

${ }^{2}$ Ryan BF, Joiner BL, Ryan TA: Minitab handbook. 2nd. Edition. Boston. Duxbury Press. 1985.

${ }^{3}$ Ciccarelli EC: A Study of 200 Cases of Anterior Chamber Implants. Ophthalmic Surgery 1985, 16: 425-32.

${ }^{4}$ Alpar JJ: A Study of the Anterior Chamber before and after Implantation of the Choyce Mark VIII Lens. Am Intra-Ocular Implant Soc J 1980, 6: 363-5.

${ }^{5}$ Kincaid MC, Green WR, Lliff LW: Granulomatous Reaction to Choyce Style Intraocular Lens. Ophthalmic Surgery, 1982, 13: 292-8.

${ }^{6}$ Rao GN, Stevens RE, Harris JK, Aquavella JV: Long-Term Changes in Corneal Endothelium Following Intraocular Lens Implantation. Ophthalmology, 1981, 88: 386-97.

${ }^{7}$ Champion R, McDonnell PJ, Green WR: Intraocular Lenses. Histopathologic Characteristics of a Large Series of Autopsy Eyes. Surv Ophthalmol 1985, 30: 1-32.

${ }^{8}$ Duffner LR, Wallace WK, Stiles WR: The Miami Cooperative Community Study on The Copeland Intraocular Lens (Pseudophakos) Am. J. Ophthalmol 1976, 82: 590-3.

${ }^{9}$ Wolter JR and Felt DP: Proliferation of Fibroblastlike Cells on Failing Intraocular Lenses. Ophthalmic Surgery, 1983, 14: 57-64.

${ }^{10}$ Richberg FA: Anterior Chamber Lenses and Severe Segmental Uveal Ectropion. Am. Intra-Ocular Impl. Soc. J. 1981, 7: 328-331.

${ }^{11}$ Neetens $A$ and Rubbens MC: Complications in Primary Anterior Chamber Pseudophakic Eyes after Intracapsular , Cataract Extraction. Ophthalmologica, 1983, 187: 83-93.

12 Pearce JL: Long-Term results of the Choyce anterior chamber lens implants Marks V, VII and VIII. $\mathrm{Br}$ J. Ophthalmol 1975, 59: 99-106.

${ }^{13}$ Kersten RC and Kolder HE: Intraocular Lens Implantation: Residents vs. Staff. Ophthalmic Surgery, 1982, 13: 470-4. 
${ }^{14}$ Southwick PC and Olson RJ: Shearing posterior chamber intraocular lenses: Five-year postoperative results. J. Am. Intraocul. Implant Soc. 1984, 10: 318-23.

${ }^{15}$ Neetens A, Dierens M, Delgadillo R: Endothelial Cell Damage after Intracapsular Cataract Extraction and Primary Anterior Chamber Pseudophakos Implantation. Ophthalmologica, 1983, 187: 114-17.

${ }^{16}$ Kaufman HE: Corneal Damage after Intraocular Surgery. Austr J Ophtalmol 1982, 9: 47-50.

${ }^{17}$ Olsen T and Eriksen JS: Corneal Thickness and Endothelial Damage after Intraocular Lens Implantation. Acta Ophthalmol 1980, 58: 773-85.

18 Junge J: Cystoid Macular Edema associated with PVP coating of an intraocular lens. Am Intraocular Implant Soc J 1980, 6: 28-29.

${ }^{19}$ Sugar J, Mitchelson J, Kraff M: The Effect of Pha- coemulsification on Corneal Endothelial Cell Density. Arch Ophthalmol 1978, 96: 446-8.

${ }^{20}$ Bourne WM and Kaufman HE: Endothelial Damage Associated with Intraocular Lenses. $\mathrm{Am}$ J Ophthalmol 1976, 81: 482-5.

${ }^{21}$ Sugar J, Mitchelson J, Kraff M: Endothelial Trauma and Cell Loss From Intraocular Lens Insertion. Arch Ophthalmol 1978, 96: 449-50.

${ }^{22}$ Levy JH and Pisacano AM: Endothelial cell loss in four types of intraocular lens implant procedures. J Am Intraocul Implant Soc 1985, 11: 465-8.

${ }^{23}$ Stur M, Grabner G, Dorda W: Changes of the corneal endothelium following intracapsular cataract extraction with implantation of semiflexible anterior chamber lenses. Acta Ophthalmol 1984, 62: 586-94.

${ }^{24}$ Smith PW, Wong SK, Stark WJ, Gottsch JD, Terry AC, Bonham RD: Complications of Semiflexible, Closed-loop Anterior Chamber Intraocular Lenses. Arch Ophthalmol 1987, 105: 52-7. 